American Journal of Applied Sciences 6 (2): 251-262, 2009

ISSN 1546-9239

(C) 2009 Science Publications

\title{
Air-Cooling Used For Metal Cutting
}

\author{
Brian Boswell, Behrad Katirachi and Tilak T Chandratilleke \\ Department of Mechanical Engineering, Curtin University of Technology, \\ GPO Box U1987, Perth Western Australia 6845
}

\begin{abstract}
Air-cooling and dry machining are both being trialled as possible solutions to the metal cutting industry's long running problems of extending tool life, reducing tool failure and minimising the heat generation at the tool tip. To date, large amounts of expensive coolant which cause both environmental damage and health hazards have had to be used. The introduction of dry machining is the goal of today's metal cutting industry that tirelessly endeavours to reduce machining costs and impact from chemicals in the environment. Modern tool tips are already capable of maintaining their cutting edge at higher temperatures, but even with these improvements in tool materials, the cutting edge will eventually break down. Applying cold air to the tool interface of these modern tool tips will also help prolong their tool life reducing the cost of metal cutting. Dry machining incorporating air being directed on to the tool interface is considered in this paper as a possible alternative for harmful liquid-based cooling. However, low convective heat removal rates associated with conventional aircooling methods are generally inadequate for dissipating intense heat generation in the cutting processes and suitable improved cooling methodologies have yet to be established.
\end{abstract}

Key words: Vortex tube, tool life, flank wear, cold fraction, coefficient of performance, air-cooled, environmentally friendly

\section{INTRODUCTION}

In this research examines the operational effectiveness of a Ranque-Hilsch vortex tube being used to cool tool tip during machining. The RanqueHilsch vortex effect was discovered in the early 1930s when it caused considerable excitement, as it demonstrated that it was possible to produce hot and cold air by supplying compressed air to a tube. At first it is hard to believe that such a device can produce hot and cold air and at a useful flow rate. The vortex tube is a simple device with no moving parts, which simultaneously produces cold and hot air streams. However, to date, there is little research in determining the efficiency of using a vortex tube in cooling tool tips. Therefore, to establish the effectiveness of the heat transfer process on the tool tip a series of experimental investigations has been carried out. These tests will determined the most suitable parameters to use, like mass flow rate of cold and hot air, cold and hot tube diameter with respect to tube length, to achievable minimum cold air temperatures.

Air-cooling has never been taken seriously by the manufacturing industry due to the fact that for many years traditional cutting fluid has been shown to be effective in cooling tool tips during the machining processes. The outcome of this research will prove that air-cooling can replace traditional cutting fluid for many machining applications, without any reduction in tool life or reduction in quality of work piece surface finish. The introduction of using a Ranque-Hilsch Vortex Tube to provide cold air to the tool interface is shown to significantly improve the performance of aircooling. Recorded tool tip interface temperatures clearly indicate that there is a highly significant reduction in tool tip temperature. This reduction in temperature slows the wear mechanisms as shown by the reduced flank wear when examined under a microscope. Therefore, monitoring the growth of the flank wear indicates the increased tool life when being air-cooled.

The Ranque-Hilsch vortex tube ${ }^{[1]}$ is a remarkable device that is able to separate airflow into two different streams simultaneously, one hotter than the inlet air and the other cooler, without any moving parts being involved. The mechanism producing the temperature separation of cold air and hot air when passing through the vortex tube is not yet fully understood. This device has been described as Maxwell's demon, a fanciful means of separating heat from cold without work. The

Corresponding Author: Brian Boswell, Department of Mechanical Engineering, Curtin University of Technology, GPO Box U1987, Perth Western Australia 6845 Tel: (08) 92663803 Fax (08) 92662681 
vortex tube basically consists of three pipes and a supply of compressed air to achieve a moderately low temperature at the cold outlet. Ranque ${ }^{[2]}$ attempted to exploit the commercial potential for this strange device that produced hot and cold air with no moving parts. Unfortunately, this venture failed and the vortex tube slipped into obscurity.

The mechanism underlying the energy transfer from the cold to the hot flow remains elusive. However, there is debate even as to the basic physics of the phenomenon, while the majority of researchers suggest the mechanism is based on the interactions of turbulence, compressibility and shear work as shown by the analysis of Deissler and Perlmutter ${ }^{[3]}$. Recent research has been divided into two categories. The first category termed as external studies were concerned with the performance of the tubes. It was found by Gulyaev $^{[4]}$ that the minimum ratio of the length of the tube to that of its diameter was thirteen. Other research suggested a ratio of forty to fifty for optimum operation. As for the diaphragm, the optimum dimension is a ratio of $2: 3$ for the diaphragm diameter to tube diameter.

The vortex tube consists of three important parts the mid-section where the air enters into the vortex generator (which increases the speed of the air), the cold tube and the hot tube as shown in Fig. 1. Normally the hot tube is about $350 \mathrm{~mm}$ long and at the end there is a conical valve which controls the amount of hot air escaping. On the right side of the vortex generator is the cold tube exit. Between the vortex generator and the cold tube there is a diaphragm, with a central hole that can be easily changed. Diaphragms with large or small holes can also increase or decrease the temperature obtained at the cold exit.

Considering the above vortex tube, the compressed air is supplied circumferentially into the tube at sonic speed and creates a cyclone (vortex) spinning at a million revolutions per minute. The air is forced to spin inward to the centre where it then escapes up along the hot tube as this path presents the least resistance to the airflow. The air continues to spin as it travels along the tube until it meets the conical valve where it turns part of the spinning air column (vortex) inside itself. The slower moving air inside column of the spinning air gives up its heat to the faster spinning outside column of air. The cold air travelling down the spinning air is now directed out the cold end of the vortex generator and the hot air is exhausted out of the other end of the vortex tube. Adjusting the conical valve built into the hot air exhaust can change the temperature of these two air streams to as low as $-55^{\circ} \mathrm{C}$ as shown by Fig. 2 .

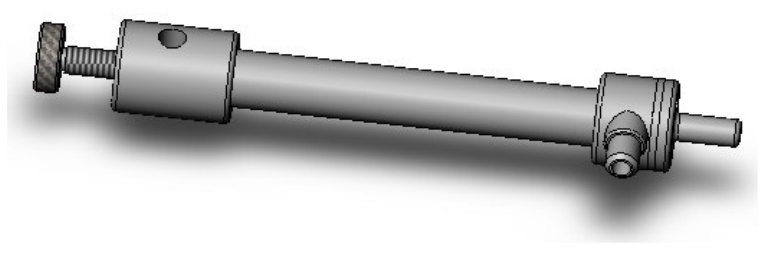

Fig. 1: Diagram of the Hilsch Vortex Tube ${ }^{[5]}$

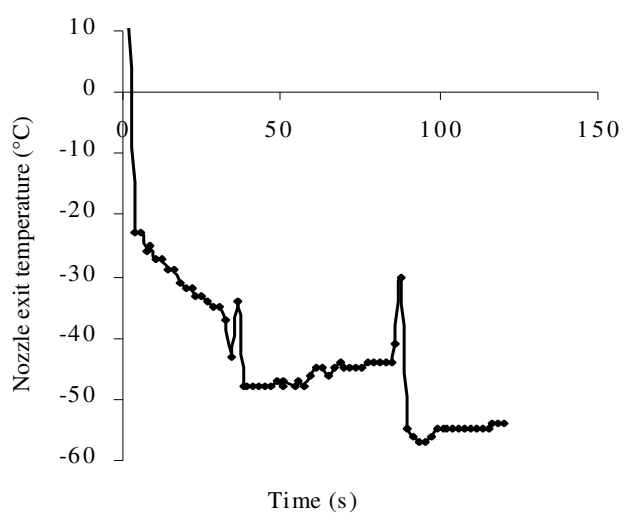

Fig. 2: Temperature recoded at cold nozzle exit having an inlet pressure of $1 \mathrm{Mpa}$

\section{VORTEX THEORY}

Currently no one can definitively explain why the vortex tube operates as it does: the process itself is straightforward as outlined by Lewins and Bejan ${ }^{[6]}$. The inlet nozzle is tangential to the vortex generator and therefore can provide a high speed rotating airflow inside the vortex generator. Subsequently, there is a radial temperature gradient increasing from the inner core of the tube to the outside wall of the tube. This is primarily because of the potential energy of compressed air converting to kinetic energy due to the forced vortex caused by the external torque near the tangential air inlet. Therefore the high-speed swirling flow inside the tube and away from the walls is created. The existing air inside the vortex hot tube is normally at the atmospheric temperature and so, when the rotating flow enters the vortex tube it expands and its temperature drops to a temperature lower than the ambient temperature. The difference between these two temperatures will lead to a temperature gradient along the tube producing colder peripheral air than the core air. As a result, the central air molecules will lose heat to those in the outer region as shown in Fig. 3. It is notable that this system is a dynamic system due to the nature of the airflow in the tube and so will not reach equilibrium. Hence the peripheral air has a higher kinetic energy (hotter) than the inner air (colder). 
Am. J. Applied Sci., 6 (2): 251-262, 2009

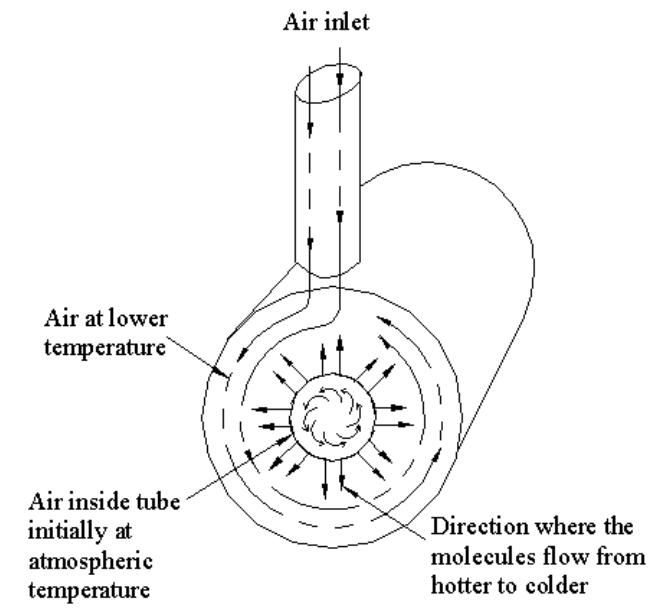

Fig. 3: Radial heat convection in vortex tube due to the expansion of the compressed air

The existence of a major pressure gradient due to the forced vortex in the radial direction will provide a centripetal force for circular swirling and therefore it will lead to a high pressure at the tube wall and low pressure at the centre. When the air enters to peripheral region (A), as it expands, the outer air will be cooled due to its expansion. Consequently, the inner core air (B) will get warm because it is compressed by the expansion of the peripheral air. Heat is then transferred from the inner core (B) to the outer core (A). As the inner air is being compressed, it naturally tries to push against the periphery by expanding. Work is therefore done on the outer core air, which then gets heated and the difference in pressures results in the expansion and contraction of the air, which causes work to be done on the peripheral air. Therefore, heat is transferred radially outward as shown in Fig. 4.

When the air continues to swirl along the tube the more energy separation will occur by axial convection while it moves towards the hot end. During this progression, the heat will be transferred from the core air to the outer air. As the airflow reaches the hot end a fraction of the air will exhaust through the conical valve, which is located at the hot end and the remaining air flow will spin back towards the cold end due to the adverse pressure gradient near the centre as shown in Fig. 5. The remaining portion of the warm air preserves its direction of motion in the vertical flow that is either in a clockwise or anticlockwise manner around the circumference of the tube. Furthermore, this air stream resides at the inner core of the tube where the air pressure there is lower.

If the angular velocities of both the air streams are preserved, it means that any two particles taken from

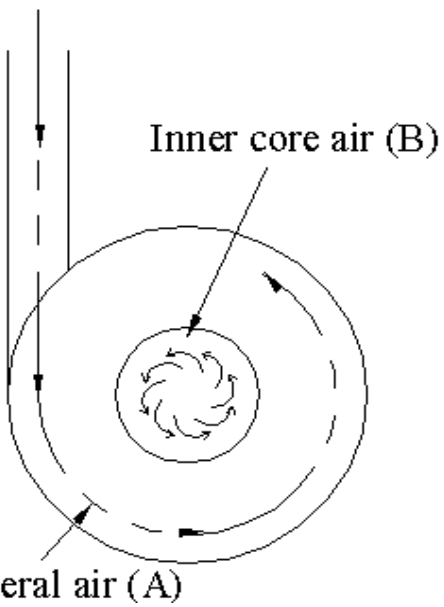

Fig. 4: Schematic positions of the peripheral and inner core air

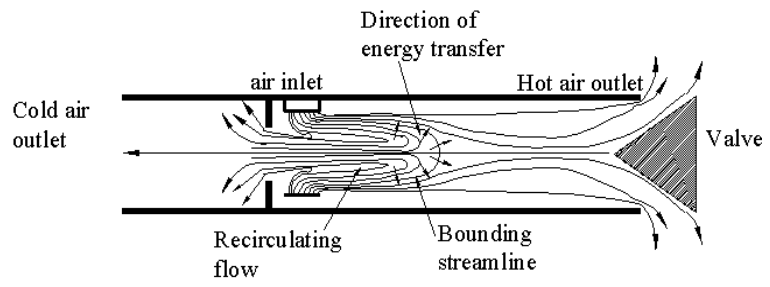

Fig. 5: A diagram of the airflow pattern in vortex tube

both the air streams will take the same time to complete a revolution around the circumference of the tube. From the principle of conservation of angular momentum, it seems that the angular velocity of the inner core molecules would increase, by the Eq:

$$
\mathrm{m}_{\mathrm{a}} \mathrm{r}_{\mathrm{a}}{ }^{2} \omega_{\mathrm{a}}=\text { constan } \mathrm{t}_{\mathrm{a}}
$$

The equation implies that in the inner core, where the value of $r_{a}$ (radial distance measured from the centre of the tube to the particular molecule in concern) is small, there should be a corresponding increase in the molecule's angular velocity, $\mathrm{w}_{\mathrm{a}}$, to allow for the conservation of the total angular momentum in the system. This is assuming that there is negligible mass difference, $\mathrm{m}_{\mathrm{a}}$, between any two-air molecules in the tube. However, the angular velocity of a particular molecule in the inner core remains unchanged. This means that angular momentum has actually been lost from the inner core of the vortex tube. Angular momentum of the inner core is not preserved or more specifically decreases, due to heat transferred to the outer core. This results in the transfer of energy from the inner core to the outer core. The loss in heat energy 
Am. J. Applied Sci., 6 (2): 251-262, 2009
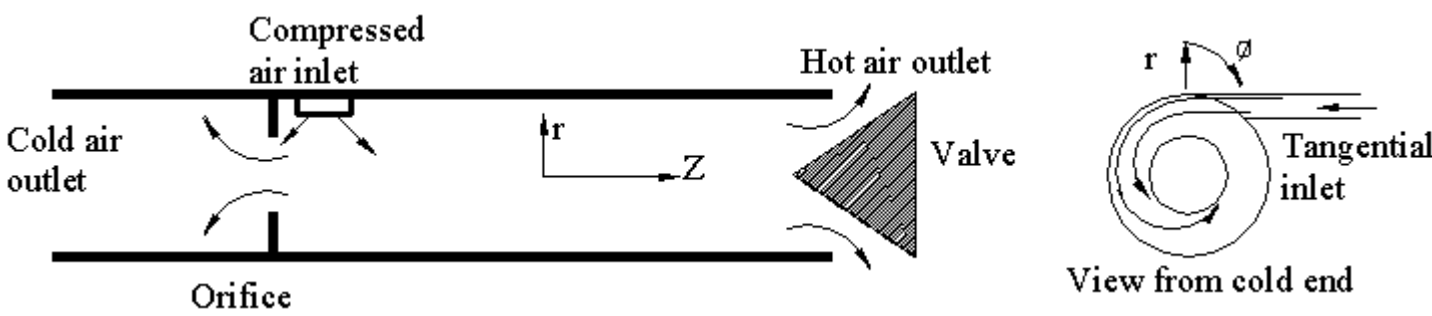

View from cold end

Fig. 6: Schematic vortex tube diagram showing tangential air inlet

from the inner core goes into heating up of the air molecules in the outer core. Hence, the outer core becomes hotter and the inner core becomes cooler. Upon reaching the hot end, the hotter peripheral air escapes through the small openings between the conical valve and the tube wall (hot outlet). However, the central air that is cooler is deflected by the tapered valve spindle and continues its travel from the hot end towards the cold tube. Only the innermost air molecules pass through the diaphragm and exit through the cold end where it is collected. As a result, the air molecules are separated into a hot stream and cold stream through the hot and cold ends of the vortex tube respectively.

The Fig. 6 shows a good view of the vortex tube. It is important to note that separation takes place specifically at the hot end tube. The purpose of the tapered spindle (conical valve) is to direct the cold air to the axial region of the tube in a counter flow. The diaphragm (orifice) on the other hand is used to block the peripheral air, so that the central flow will escape through the cold end.

The absence of moving parts in the vortex tube may create this wrong supposition that this phenomenon is violating thermodynamics law. The fact that without doing any work at room temperature, a stream of air can be divided into two different steams, one cooler and one hotter, seems to contradict the second law of thermodynamics. However, it is important to mention that despite this misleading belief the physics remains intact. Although, the physics of the vortex tube is complicated, the study of the basic principles of thermodynamics can help to gain a better understanding of what is happening inside a vortex tube.

The first law of thermodynamics is about the conservation of energy. According to this law, during a reaction between a system and it's ambient, the energy that can be received from the ambient to the system is exactly equal to the energy that is lost from the system to the ambient. This energy can be seen in two different states: Heat and Work. Hence, for every thermodynamics system with a specific control volume:

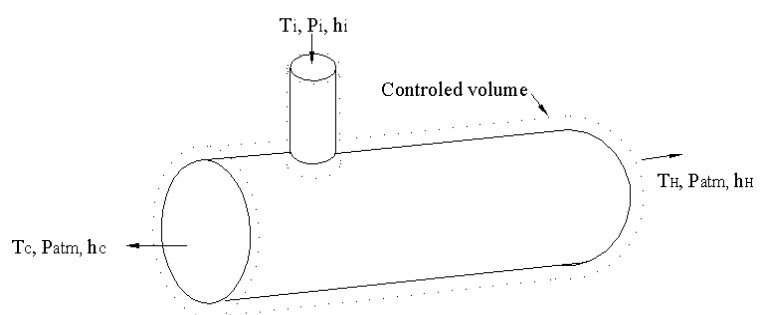

Fig. 7: Schematic control volume of a vortex tube

$$
\begin{aligned}
& \dot{\mathrm{Q}}_{\mathrm{C} . \mathrm{V}}+\sum \dot{\mathrm{m}}_{\mathrm{i}}\left(\mathrm{h}_{\mathrm{i}}+\frac{\mathrm{v}_{\mathrm{i}}^{2}}{2}+\mathrm{gz}_{\mathrm{i}}\right)= \\
& \sum \dot{\mathrm{m}}_{\mathrm{e}}\left(\mathrm{h}_{\mathrm{e}}+\frac{\mathrm{v}_{\mathrm{e}}^{2}}{2}+\mathrm{gz}_{\mathrm{e}}\right)+\dot{\mathrm{W}}_{\mathrm{c} . \mathrm{v}}
\end{aligned}
$$

where $\dot{\mathrm{Q}}_{\mathrm{cv}}$ is the rate of heat flow, which transfers through the control volume boundary and $\dot{\mathrm{W}}_{\mathrm{cv}}$ is the work that can be done by the system on it's ambient, m is the mass flow rate, $\mathrm{h}$ is the enthalpy of the air stream, $\mathrm{v}$ is the air stream velocity, $\mathrm{z}$ is the distance between the air stream and a source point and the subscripts $i$ and $e$ refer to inlet and outlet streams.

Assuming that the vortex tube is well insulated, then the heat transfer between the system and the ambient can be taken as $\dot{\mathrm{Q}}_{\mathrm{cv}}$ equal to zero, with $\mathrm{v}_{\mathrm{i}}$ and $\mathrm{v}_{\mathrm{e}}$ also equal to zero, as can the work W. Considering the control volume as shown in Fig. 7 for the vortex tube then Eq. (2) can be simplified as:

$$
\sum \dot{\mathrm{m}}_{\mathrm{i}} \mathrm{h}_{\mathrm{i}}=\sum \dot{\mathrm{m}}_{\mathrm{e}} \mathrm{h}_{\mathrm{e}}
$$

The expanding air can be treated as ideal gas and hence with no Joule-Thomson heating or cooling effect. Also, assuming air obeys the ideal gas laws and having constant specific heat capacity $\mathrm{C}_{\mathrm{p}}$, you can write:

$$
\begin{aligned}
& \mathrm{h}_{\mathrm{i}}=\mathrm{C}_{\mathrm{p}} \mathrm{T}_{\mathrm{i}} \\
& \dot{\mathrm{m}}_{\mathrm{i}} \mathrm{C}_{\mathrm{p}} \mathrm{T}_{\mathrm{i}}=\dot{\mathrm{m}}_{\mathrm{c}} \mathrm{C}_{\mathrm{p}} \mathrm{T}_{\mathrm{c}}+\dot{\mathrm{m}}_{\mathrm{h}} \mathrm{C}_{\mathrm{p}} \mathrm{T}_{\mathrm{h}}
\end{aligned}
$$


by defining $\mu_{\mathrm{cf}}$ as the cold fraction:

$$
\mu_{\mathrm{cf}}=\frac{\dot{\mathrm{m}}_{\mathrm{c}}}{\dot{\mathrm{m}}_{\mathrm{i}}}
$$

from the continuityEq:

$$
\dot{\mathrm{m}}_{\mathrm{c}}+\dot{\mathrm{m}}_{\mathrm{h}}=\dot{\mathrm{m}}_{\mathrm{i}}
$$

Combining Eq. 5, 6 and 7 gives the relationship between inlet stream temperature and cold stream temperature, (hot stream temperature and cold fraction). Hence Eq:

$$
\mathrm{T}_{\mathrm{i}}=\mu_{\mathrm{cf}} \mathrm{T}_{\mathrm{c}}+(1-\mu) \mathrm{T}_{\mathrm{h}}
$$

by assuming,

$$
\begin{aligned}
& \Delta \mathrm{T}=\mathrm{T}_{\mathrm{h}}-\mathrm{T}_{\mathrm{c}} \\
& \Delta \mathrm{T}_{\mathrm{c}}=\mathrm{T}_{\mathrm{i}}-\mathrm{T}_{\mathrm{c}} \\
& \Delta \mathrm{T}_{\mathrm{h}}=\mathrm{T}_{\mathrm{h}}-\mathrm{T}_{\mathrm{i}}
\end{aligned}
$$

where, $\Delta \mathrm{T}$ is the difference between the hot and the cold air stream temperatures, $\Delta \mathrm{T}_{\mathrm{c}}$ is the temperature difference between the inlet and cold air streams and finally $\Delta \mathrm{T}_{\mathrm{h}}$ is the temperature difference between the inlet and hot air streams. The equation can be written as:

$$
\Delta \mathrm{T}=\Delta \mathrm{T}_{\mathrm{h}}-\Delta \mathrm{T}_{\mathrm{c}}
$$

Combining Eq. 8 and 12 allows you to determine $\Delta \mathrm{T}_{\mathrm{c}}$ and $\Delta \mathrm{T}_{\mathrm{h}}$ theoretically by measuring the cold fraction, $\mu_{\mathrm{cf}}$ and total temperature difference, $\Delta \mathrm{T}$. Therefore:

$$
\begin{aligned}
& \Delta \mathrm{T}_{\mathrm{c}}=\left(1-\mu_{\mathrm{cf}}\right) \Delta \mathrm{T} \\
& \Delta \mathrm{T}_{\mathrm{h}}=\mu_{\mathrm{cf}} \Delta \mathrm{T}
\end{aligned}
$$

Equation 13 and 14 can be used to show the consistency of the first law of thermodynamics for test carried out on the vortex tube.

\section{VORTEX TUBE EFFICIENCY}

In practical cases of refrigeration it is so important to determine the coefficient of performance of the cooling device. Hence, it seems only logical to determine the coefficient of performance of the vortex tube and compare it with the conventional refrigeration coefficient of performance to determine its efficiency in use. The vortex tube can be used as a refrigeration device when the cold pipe wall is used to reduce the temperature or as a heating device when the hot pipe wall is used to increase the temperature of an enclosure. It should be noted that opposite to what is normally viewed in thermodynamics, the vortex tube in this case is an open control volume device. If the system was assumed to be steady state, then from the first law of thermodynamics:

$$
\Delta \dot{\mathrm{H}}=\dot{\mathrm{Q}}
$$

where, $\Delta \dot{\mathrm{H}}$ is the system enthalpy change and $\dot{\mathrm{Q}}$ is the heat exchanged between the system and its surroundings. Let's assume that $\dot{Q}$ is approximately zero even though the cold tube may have frost on it and the hot tube is very warm. If this is the case then:

$$
\Delta \mathrm{H}=\Delta \mathrm{H}_{\mathrm{c}}+\Delta \mathrm{H}_{\mathrm{H}}=0
$$

where, $\Delta \mathrm{H}_{\mathrm{c}}$ is the enthalpy change of cold stream and $\Delta \mathrm{H}_{\mathrm{H}}$ is the enthalpy change of hot stream. Assuming the air as an ideal gas, the total enthalpy change can be written as:

$$
\Delta \mathrm{H}=\mathrm{m}_{\mathrm{c}} \mathrm{C}_{\mathrm{p}}\left(\left(\mathrm{T}_{\mathrm{c}}-\mathrm{T}_{\mathrm{i}}\right)+\mathrm{m}_{\mathrm{h}} \mathrm{C}_{\mathrm{p}}\left(\mathrm{T}_{\mathrm{h}}-\mathrm{T}_{\mathrm{i}}\right)=0\right.
$$

where, $\mathrm{m}_{\mathrm{c}}$ is mass flow rate at cold tube, $\mathrm{m}_{\mathrm{h}}$ is mass flow rate at hot tube, $T_{c}$ is cold air temperature, $T_{i}$ is inlet air temperature, $T_{h}$ is hot air temperature and $C_{p}$ is specific heat of air at constant pressure and assumes the process as reversible and adiabatic. By applying the second law of thermodynamics to the above:

$$
\Delta \mathrm{S}=\int \frac{1}{\mathrm{~T}} \mathrm{dq}=0
$$

where, $\Delta \mathrm{S}$ is total entropy change, $\mathrm{q}$ is heat transfer and $\mathrm{T}$ is absolute temperature.

The actual entropy change of the control volume at steady state is:

$$
\Delta \mathrm{S}=\Delta \mathrm{S}_{\mathrm{c}}+\Delta \mathrm{S}_{\mathrm{h}}
$$

where, $\Delta \mathrm{S}_{\mathrm{c}}$ and $\Delta \mathrm{S}_{\mathrm{h}}$ are the entropy change from entrance to exit of the portion of entering air which leaves the cold tube and the portion of entering are 
which leaves the hot tube, respectively. For an ideal gas (air) with constant specific heat, the entropy change can be written as:

$$
\Delta S=\frac{\dot{\mathrm{m}}_{\mathrm{c}}}{\dot{\mathrm{m}}_{\mathrm{i}}}\left[\mathrm{C}_{\mathrm{p}} \ln \frac{\mathrm{T}_{\mathrm{c}}}{\mathrm{T}_{\mathrm{i}}}+\mathrm{R} \ln \frac{\mathrm{P}_{\mathrm{i}}}{\mathrm{P}_{\mathrm{c}}}\right]+\frac{\dot{\mathrm{m}}_{\mathrm{h}}}{\dot{\mathrm{m}}_{\mathrm{i}}}\left[\mathrm{C}_{\mathrm{p}} \ln \frac{\mathrm{T}_{\mathrm{h}}}{\mathrm{T}_{\mathrm{i}}} \mathrm{R} \ln \frac{\mathrm{P}_{\mathrm{i}}}{\mathrm{P}_{\mathrm{h}}}\right] \text { (20) }
$$

where the subscripts $\mathrm{i}, \mathrm{c}$ and $\mathrm{h}$ are respectively inlet stream, cold stream and hot stream and $\mathrm{R}$ is the ideal gas (air) constant.

Since the appearance of a cold (or hot) effect upon the pipe wall without moving parts would attempt to consider this device as competition for a refrigerator (or heat pump), it is useful to estimate its coefficient of performance (COP). Focusing on the cooling effect that can be achieved by placing the cold pipe within an enclosure, the coefficient of performance can be calculated by:

$$
\mathrm{COP}=\frac{\Delta \dot{\mathrm{H}}_{\mathrm{c}}}{\dot{\mathrm{W}}}
$$

Where $\Delta \dot{\mathrm{H}}_{\mathrm{c}}$ is obtained from:

$$
\Delta \dot{\mathrm{H}}_{\mathrm{c}}=\dot{\mathrm{m}}_{\mathrm{c}}\left(\mathrm{T}_{\mathrm{i}}-\mathrm{T}_{\mathrm{c}}\right)
$$

$\Delta \dot{\mathrm{H}}_{\mathrm{c}}$ is equal to the heat that is transferred to the cold stream through the cold pipe wall (like a heat exchanger) from some source (like the cold box in a refrigerator) and $\dot{W}$ in the present case is the work done to compress the air from atmospheric pressure and temperature to the inlet conditions of the tube. Assuming reversible compression (isentropic, minimum work), $\dot{\mathrm{W}}$ is then obtained from:

$$
\dot{\mathrm{W}}=\frac{\dot{\mathrm{mR}}\left(\mathrm{T}_{2}-\mathrm{T}_{1}\right) \mathrm{n}}{\mathrm{n}-1}
$$

where, $T_{2}$ is the compressor exit temperature and $T_{1}$ is the compressor inlet temperature (reversible, polytropic process; air: $\mathrm{n}=1.4$ ). If we consider a complete system, $\mathrm{P}_{1}$ and $\mathrm{T}_{1}$ are the atmospheric pressure and temperature, $\mathrm{P}_{2}$ and $\mathrm{T}_{2}$ are the compressor exit conditions,

$$
\frac{\mathrm{P}_{2} \frac{\mathrm{n}-1}{\mathrm{n}}}{\mathrm{P}_{1}}=\frac{\mathrm{T}_{2}}{\mathrm{~T}_{1}}
$$

After the air is compressed, it is kept in the highpressure tank where then it cools down to the atmosphere temperature, $\mathrm{T}_{1}$ so the inlet temperature of the sonic nozzle $T_{i}$, is equal to $T_{1}$ noting that:

$$
\frac{\mathrm{Rn}}{\mathrm{n}-1}=\mathrm{C}_{\mathrm{p}}
$$

Equation (23) can be simplified to:

$\dot{\mathrm{W}}=\dot{\mathrm{m}}_{\mathrm{i}} \mathrm{C}_{\mathrm{p}}\left(\mathrm{T}_{2}-\mathrm{T}_{1}\right)(26)$

with $\mathrm{T}_{2}$ calculated from Eq. (24). This is an ideal work value so it is less than the actual work needed to drive the compressor. By considering the above equations and using the Eq. (21), the coefficient of performance of the vortex tube can be determined.

\section{EXPERIMENTAL ANALYSIS OF VORTEX TUBE DESIGN}

To help compare a number of the vortex tube parameters it is useful to use the cold mass fraction as this can be contrasted over the range of vortex tube tests. This parameter is simply the ratio of air mass flow rate at the cold end of the tube to the mass flow rate of the compressed air at inlet. It is important to note that the air mass flow rate at the hot end of the tube is varied from its maximum value (which is equal to the mass flow rate of the compressed air) to its minimum value (which is equal to zero) and is shown on the horizontal axis on the graphs. By the law of the conservation of mass, the mass flow rate at the cold end is equal to the difference of the inlet mass flow rate and the mass flow rate at the cold end. Therefore, by varying the mass flow rate at the hot end, you effectively control the mass flow rate at the cold end from its minimum to its maximum value.

$$
\text { Cold Mass Fraction }=\frac{\dot{\mathrm{m}}_{\mathrm{c}}}{\dot{\mathrm{m}}_{\mathrm{in}}}=\frac{\dot{\mathrm{m}}_{\mathrm{in}}-\dot{\mathrm{m}}_{\mathrm{h}}}{\dot{\mathrm{m}}_{\mathrm{in}}}
$$

Where:

$\dot{\mathrm{m}}_{\mathrm{c}}=$ Air mass flow rate at cold end

$\dot{\mathrm{m}}_{\mathrm{h}}=$ Air mass flow rate at hot end

$\dot{\mathrm{m}}_{\mathrm{h}}=$ Mass flow rate of compressed air at inlet

Cold mass fraction is the percentage of input compressed air that is released through the cold end of the tube. Generally, the less cold air being released, the colder the air will be. Adjusting the control valve knob will vary the cold mass fraction. High cold mass fraction would give a greater airflow, but does not give 
the lowest possible temperature. The high cold mass fraction combination of airflow and cold temperature produces the maximum refrigeration capacity. A low cold mass fraction on the other hand means a smaller volume of air coming out that is very cold. In short, the less air to be released, the colder the air becomes. The effect of velocity on the temperature drop at the cold end is important since if the velocity that produces the lowest temperature drop is known, then the compressed air pressure and the cold nozzle diameter could be optimised. A decrease in the nozzle diameter would also force the air to flow towards the direction of the hot end and would lead to an improvement in the vortex tube efficiency to some extent.

$$
\begin{aligned}
& \dot{\mathrm{m}} .=\frac{\rho \mathrm{AL}}{\mathrm{t}}=\rho \mathrm{Av} \\
& \mathrm{v}=\frac{\dot{\mathrm{m}}}{\rho \mathrm{A}}
\end{aligned}
$$

Where:

$$
\begin{aligned}
\dot{\mathrm{m}} & =\text { Mass flow rate, } \mathrm{kg} \mathrm{s}^{-1} \\
\rho & =\text { Density, } \mathrm{kg} \mathrm{m}^{-3} \\
\mathrm{v} & =\text { Velocity, } \mathrm{m} \mathrm{s}^{-1}
\end{aligned}
$$

The coefficient of performance estimation can be used to give a good measure of the refrigeration performance of the cooling system, which can be used in determining the performance of the vortex tube.

The coefficient of performance for this vortex tube was calculated by using Eq. (21) and was found to give a value of 1.38. This value is low when compared with a conventional refrigeration system, which are normally around 3.5. However, even though this shows that a vortex tube is not an ideal device for an air conditioning system, it is still suitable for spot cooling.

Tests on the design of the vortex tube show that the temperature drop at the cold stream is a function of cold mass fraction as shown by Eq. (27). From these tests it is shown that nozzle one produces the biggest temperature drop as shown by Fig. 9. This nozzle had the smallest diaphragm diameter $(3 \mathrm{~mm}$ diameter) between the vortex generator and the cold tube. It can be concluded from these tests the smaller the diameter at the cold exit of the vortex generator, the bigger the temperature drop.

Examination of (Fig. 8-11b) shows the trend that the lowest temperatures occur at the low cold mass fraction. Unfortunately, the flowmeter was not capable of measuring the cold mass fraction near zero. Therefore it was not possible to find the exact cold

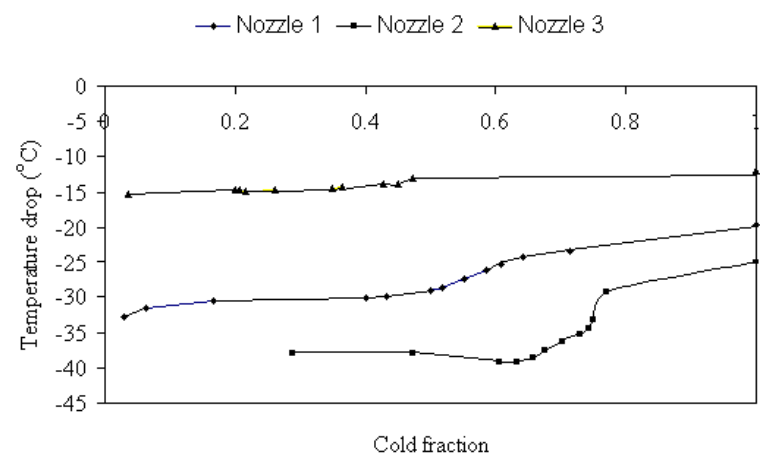

Fig. 8: Nozzle temperature drop with respect to cold fraction

$\rightarrow$ Nozzle $2 \rightarrow$ Nozzle $1 \rightarrow$ Nozzle 3

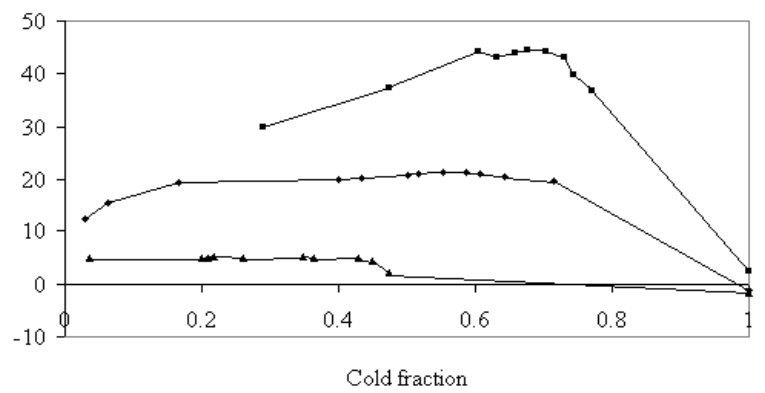

Fig. 9: Nozzle diameter effects on temperature

mass fraction where the lowest temperature occurs. Although, from the graphs it is possible to assume that this value will be between 0 and 0.1 . The biggest temperature drop at the cold air outlet with highest air hot outlet temperature increase was shown to have cold mass fraction between 0.6 and 0.7 when using nozzle 1 , as shown on Fig. 8. The trend shown for the different nozzle diameter all graphs in Fig. 9 show that from $0=$ $\mu$ all graphs start increasing to a highest point and then there is a decline in temperature.

This manner was predictable as it is known that at low cold mass fraction, a high fraction of inner swirling air flow joins the outer air flow at the hot outlet and therefore the temperature of the hot air stream decreases. As the conical valve gradually opens, a higher portion of the air escapes out the hot exit, while the rest of the air is returned back towards the cold end through the middle of the vortex air. This allows the temperature of the hot air stream to increase to its optimum point as well as generating the optimum cold air. Continuing to open the conical valve beyond its optimum position allows additional air to escape through the hot exit with a reduced temperature. 
Am. J. Applied Sci., 6 (2): 251-262, 2009

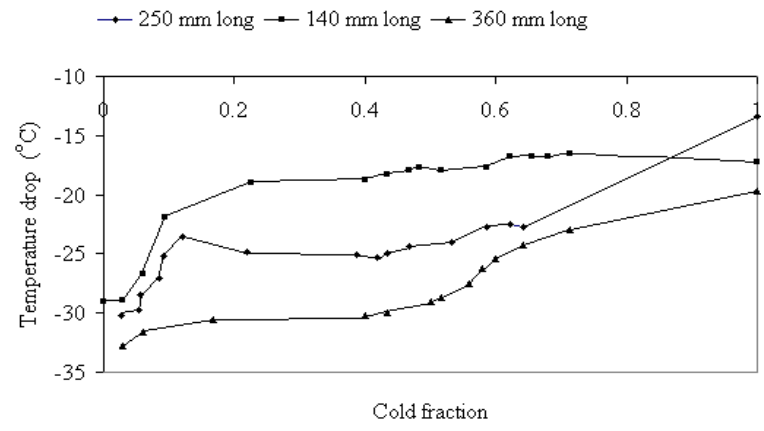

Fig. 10a:Temperature drop at cold exit with respect to tube length

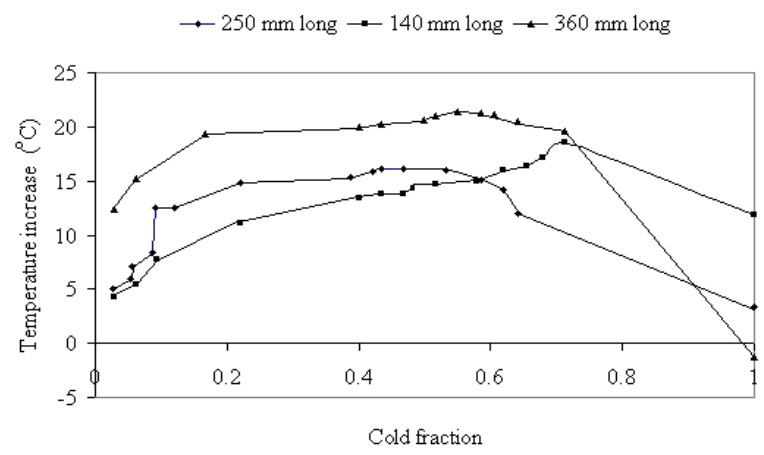

Fig. 10b:Temperature rise at hot exit with respect to tube length

The length of the hot tube has an important effect on the energy separation in the vortex tube, as can be shown in (Fig. 10a, b). For example, by increasing the length of the hot tube, the temperature drop increases. This is due to the air inner flow having more time to transfer energy to the outer airflow. However, beyond the optimum length of the hot tube the temperature drop starts to decrease as shown by tests carried out on a vortex tube larger than $360 \mathrm{~mm}$. This reduction in temperature drop was caused by the energy transfer becoming inversed as the outer hot flow starts warming up the inner flow and when the inner flow reaches the conical valve, it returns back towards the cold end at a higher temperature.

From the tests it can be concluded that the maximum temperature increase for all lengths can be achieved by the cold mass fraction between 0.4 and 0.7 .

Another important parameter that has great effect on the vortex tube is pressure, as shown in (Fig. 11a, b), which shows that generally by increasing the pressure you get a larger temperature drop. Sadi and Yazdi ${ }^{[7]}$ also found from their research that by increasing the tube length the temperature difference increases and energy destruction decreases.

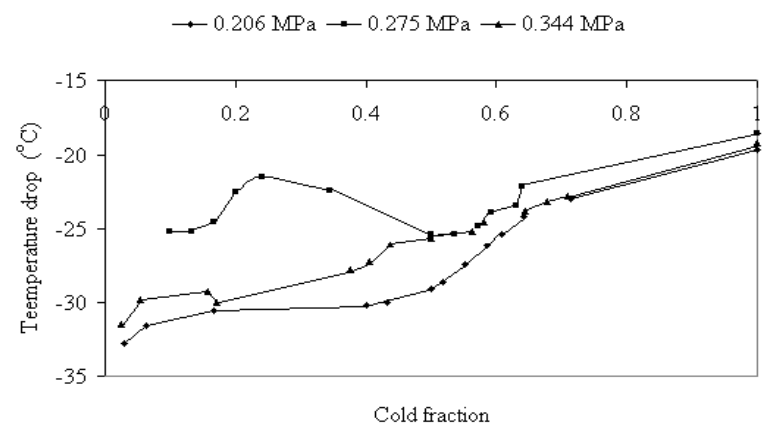

Fig. 11a: Temperature drop with respect to pressure

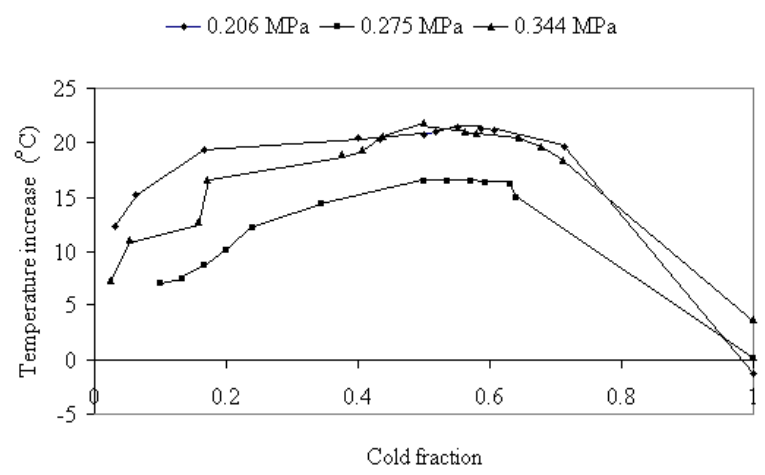

Fig. 11b: Temperature increase with respect to pressure

The trends obtained are similar to those that Stephan ${ }^{[7]}$ obtained in his experiments that is, the temperature increased between $\mu=0.8$ and $\mu=0.95$. For this vortex tube the maximum values was found to be between $\mu=$ 0.5 and $\mu=0.7$, as shown in Fig. $11 \mathrm{~b}$. The reduction of the cold fraction for these tests compared with Stephan being accounted to the geometrical differences of the vortex tube tested.

\section{AIR-COOLED METAL CUTTING}

The positions of the thermocouples imbedded in the tool tip are shown on Fig. 12, with the temperature closest to the tool interface being measured by thermocouple on channel 13 (Ch13). Figure 13 shows the vortex tube, generated cold air being directed onto the tool interface during the metal cutting tests. The air-cooling performance of this process can now be evaluated by determining the effect on tool life Ay et al. ${ }^{[8]}$ for this machining condition.

The temperatures shown in Fig. 14 were measured at the tool tip prior to machining, with two of the thermocouples recording temperatures of $-5^{\circ} \mathrm{C}$, as indicated by thermocouples on channel (Ch13) and (Ch15). 


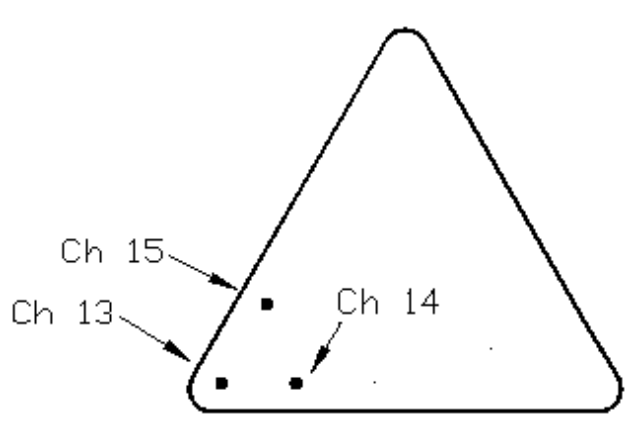

Fig. 12: Position of thermocouples in tool tip

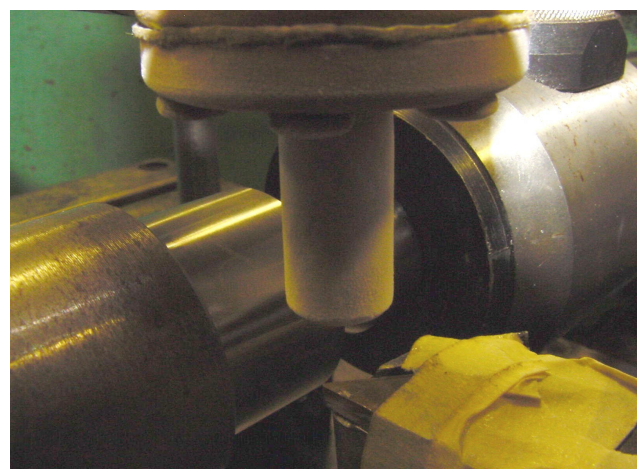

Fig. 13: Vortex tube being used to cool tool tip

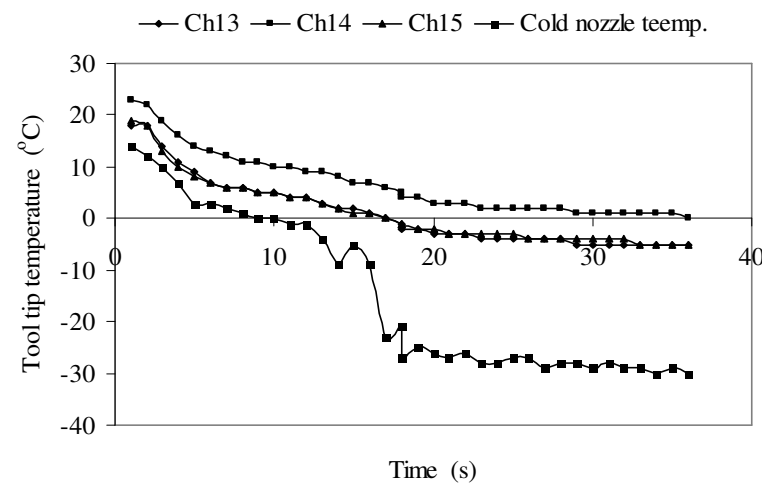

Fig. 14: Tool tip temperatures before machining has commenced. The vortex tube used a $3 \mathrm{~mm}$ diameter orifice plate at a pressure of $0.8 \mathrm{MPa}$

When the vortex exit air has reached approximately $-30^{\circ} \mathrm{C}$, machining is commenced. As indicated by the rise in the tool tip temperatures ${ }^{[9]}$, the tool tip rises to a steady state temperature of $60^{\circ} \mathrm{C}$ as shown in Fig. 15 . The temperature drop at the end indicates the point when the feed is stopped and no more chips are being generated. This allows the cooling air to flow unimpeded across the tool tip giving a better heat

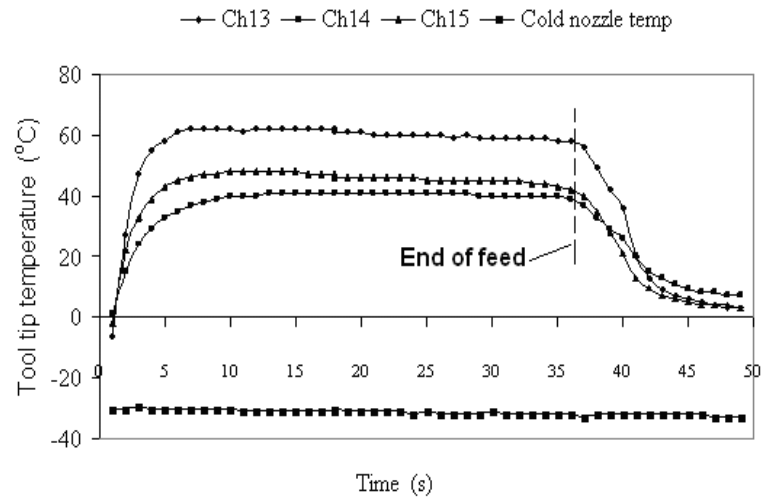

Fig. 15: The graph shows the tool tip temperatures during machining, and after the tool feed has stopped cutting

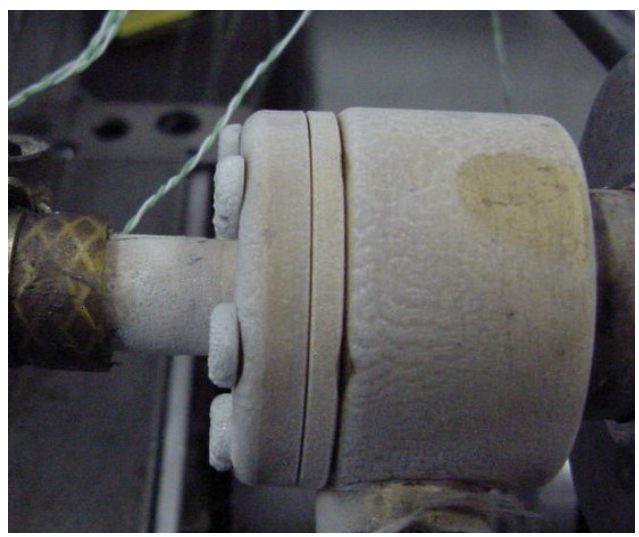

Fig. 16: Picture showing frost on the outside of the cold tube

dissipation from the tool reducing the temperature of the tool rapidly Fig. 16.

The build up of frost on the vortex tube during the cutting tests can be clearly seen confirming that the vortex tube is delivering very cold air.

\section{EFFECT OF AIR-COOLING ON TOOL LIFE}

It is known that all the wear mechanisms increased at elevated temperatures reducing the tool life ${ }^{[10]}$. The application of cold air to the tool tip is shown to reduce the temperature at the tool tip enabling the tool tip to have a longer tool life ${ }^{[11]}$. The effectiveness of the air-cooled system can be shown when a comparison is made between the wear for a dry cut and an air-cooled cut for one minute and seven minutes of machining. Figure 17a-d shows the flank wear as seen under a microscope with a 63 optical magnification setting. 


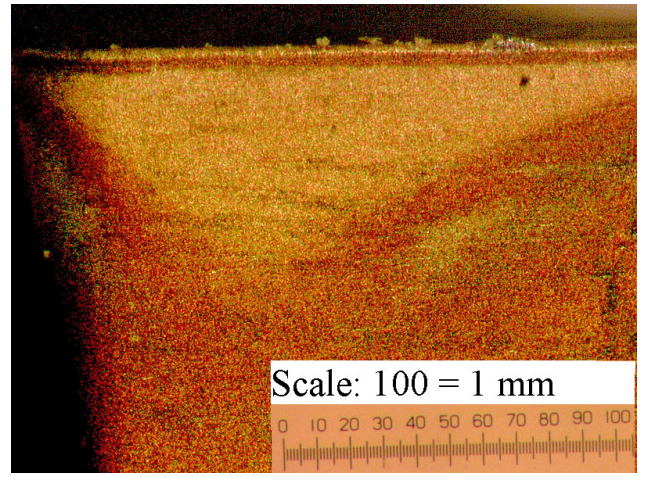

Fig. 17a:Picture showing flank wear for a dry cut after 1 minute of machining at a cutting speed of $190 \mathrm{~m} \mathrm{~min}^{-1}$ and feed rate of $0.23 \mathrm{~mm} / \mathrm{rev}$ with a $2 \mathrm{~mm}$ depth of cut

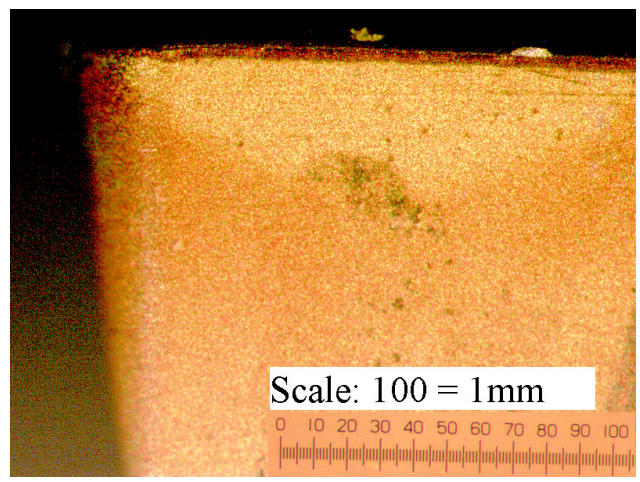

Fig. 17b: Picture showing flank wear for a air-cooled cut after 1 minute of machining at a cutting speed of $190 \mathrm{~m} \mathrm{~min}^{-1}$ and feed rate of 0.23 $\mathrm{mm} / \mathrm{rev}$ with a $2 \mathrm{~mm}$ depth of cut

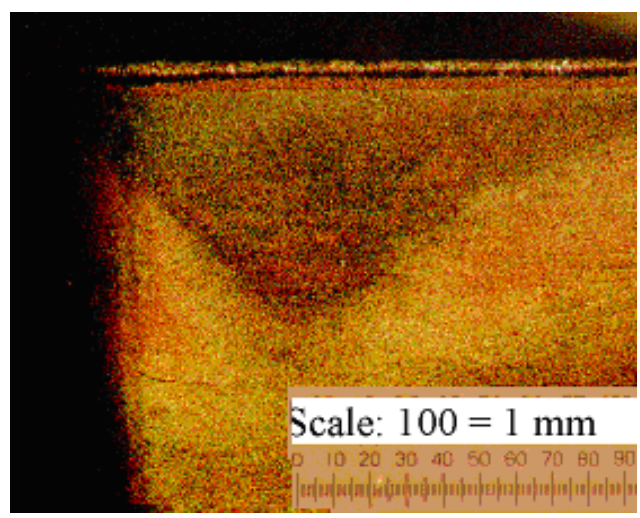

Fig. 17c: Picture showing flank wear for a dry cut after 7 minute of machining at a cutting speed of $190 \mathrm{~m} \mathrm{~min}^{-1}$ and feed rate of $0.23 \mathrm{~mm} / \mathrm{rev}$ with a $2 \mathrm{~mm}$ depth of cut

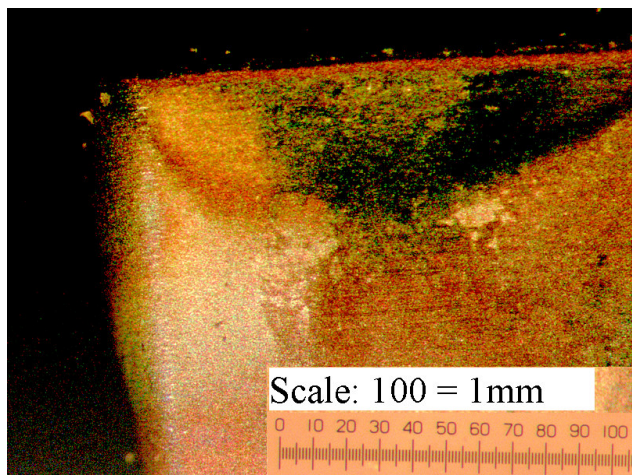

Fig. 17d: Picture showing flank wear for a air-cooled cut after 7 minutes of machining at a cutting speed of $190 \mathrm{~m} \mathrm{~min}^{-1}$, and feed rate of 0.23 $\mathrm{mm} / \mathrm{rev}$ with a $2 \mathrm{~mm}$ depth of cut

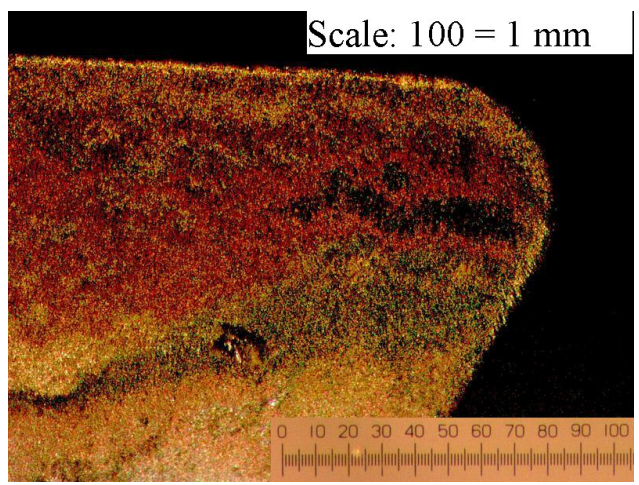

Fig. 18a: Picture showing top rake face wear for a dry cut after 7 minutes of machining at a cutting speed of $190 \mathrm{~m} \mathrm{~min}^{-1}$, and feed rate of 0.23 $\mathrm{mm} / \mathrm{rev}$ with a $2 \mathrm{~mm}$ depth of cut

The development of the flank wear was shown to take longer to develop when the cooled air was applied to the cutting zone as shown in Fig. 17d.

After seven minutes of dry machining the top rake face is starting to develop crater wear, at $0.5 \mathrm{~mm}$ from the flank face as shown in Fig. 18a. Further dry machining will accelerate this rate of wear. At this stage the tool radius shows no sign of wear and the top flank edge has no observable notches.

The air-cooled tool tip shows no visible sign of tool wear on the top rake face and the flank wear is also substantially reduced. Observation of the chips produced during dry and air-cooling indicated that much of the heat was being dissipated from the cutting zone. Figure 19 shows the chips produced during the dry and air-cooled tool tip test.

The left hand chips produced during dry cutting and the right hand produced during air-cooling. 
Am. J. Applied Sci., 6 (2): 251-262, 2009

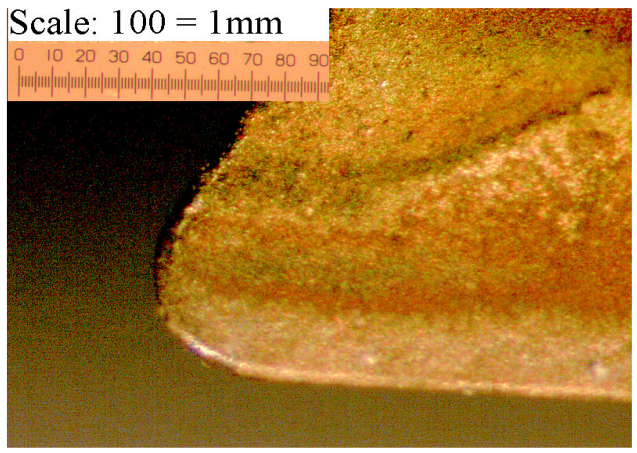

Fig. 18b: Picture showing top rake face wear for aircooled cut after 7 minutes of machining at a cutting speed of $190 \mathrm{~m} / \mathrm{min}$, and feed rate of $0.23 \mathrm{~mm} / \mathrm{rev}$ with a $2 \mathrm{~mm}$ depth of cut

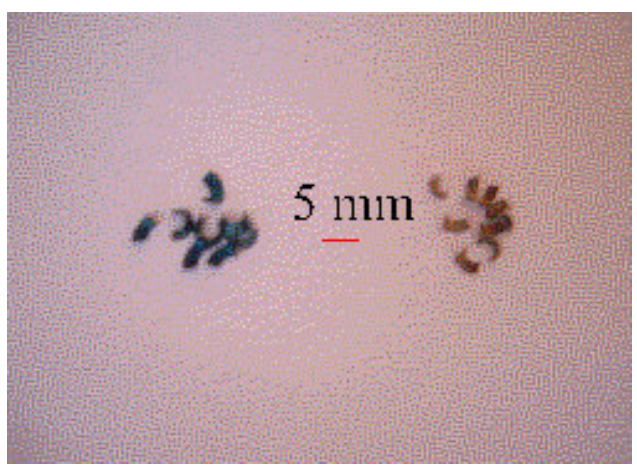

Fig. 19: Picture showing chips produced by a $2 \mathrm{~mm}$ depth of cut at 0.23 feed rate, and cutting speed of 190 $\mathrm{m} \min ^{-1}$

\section{CONCLUSION}

Previous researchers such as Liu et al. ${ }^{[12]}$ proved that compressed air did not achieve as good heat dissipation as oil water emulsion or water vapour from the tool interface. However, the results obtained from using compressed air combined with the vortex tube have shown that this method of cooling the tool interface is effective and compares exceedingly well with traditional cooling methods.

The temperature recoded during air-cooling was found to be $60^{\circ} \mathrm{C}$ which is $40^{\circ} \mathrm{C}$ cooler than that obtained during traditional wet machining and $210^{\circ} \mathrm{C}$ cooler than dry machining as shown by Fig. 20. These temperatures were measured $1 \mathrm{~mm}$ from the tool interface and for that reason the temperatures recorded at this position are considerably reduced from that of the tool interface. However, it must be assumed that the temperature will be reduced at the tool interface as well as the measured points in the tool.

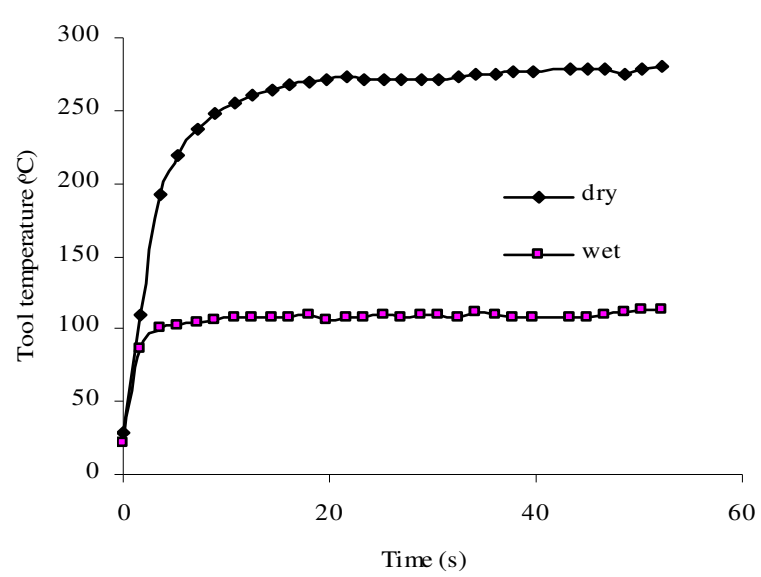

Fig. 20: Temperatures recoded at the tool tip for dry and air-cooling

The most convenient method of determining the effectiveness of the air-cooling is by determining the tool life, as it is known that there is a relationship between tool life and the wear mechanisms that are shown to increase at elevated cutting temperatures. Inspection of the tool tip using a microscope confirmed that the tool wear is reduced when being air-cooled, resulting in longer tool life. The vortex tube air-cooling systems proved to be effective at dissipating the heat from the tool tip, proving that air-cooling is an effective method of cooling tool tips. Therefore, whenever dry machining is the preferred method of metal cutting, aircooling should be incorporated as there are no associated environmental issues and will extend the life of the tool.

\section{REFERENCES}

1. Silverman, M.P., 1993. The Wirbelrohr's Roar. Cambridge University Press, Chpt 6, pp: 221-240.

2. Ranque, G., 1993. Experiences sur la détente giratore avec productions simulanees d'un echappement d'air chaud et d'um echappement d'air froid. Bull. Soc. France Phys., 1128: (J. Phys. Radium, 4, Ser.7).

3. Dissler, R.G. and M. Permutter, 1960. Analysis of the flow and energy separation in a turbulent vortex. Int. J. Heat Mass Transfer, 1: 173-191.

4. Gulyaev, A., 1966. Vortex tube and the vortex effect, soviet physics. Tech. Phys., 10 (10): 326-331.

5. Hilsch, R., 1947. The use of the expansion of gases in a centrifugal field as cooling process. Rev. Sci. Instrum., 18 (2): 108-1113.

6. Lewins J. and A. Benjan, 1999. Vortex tube optimisation theory. J. Energy, 24: 931-943. 
7. Saidi, M.H. and M.R. Allaf Yazdi, 1999. Energy model of a vortex tube system with experimental results. J. Energy, 24: 625-632.

8. Ay, H. and W.J. Yang, 1998. Heat transfer and life of metal cutting tools in turning. Int. J. Heat Mass Trans., 41: 613-623.

9. O'Sullivan, D. and M. Cotterell, 2001. Temperature measurement in single turning point. J. Master. Proc. Tech., 118: 301-308.
10. Young, H.T., 1996. Cutting temperatures to flank wear. Wear, 201: 117-120.

11. Cook, N., 1973. Tool wear and tool life. ASME Tran. J. Energy. Ind., 95: 931-938.

12. Liu, J., 2005. Research on experiments and action mechanism with water vapour as coolant and lubricant in green cutting, Int. J. Mach. Tools Manuf., 45: 687- 694. 